time to take effect. Our patients described their recovery in terms of a "cracked mirror" 10-15 minutes after the injection. Angiography was performed 60 minutes after injection and showed complete reopening.

With regard to the adverse side effects mentioned by Pandit and Tiamiyu, cardiac arrhythmias were reported after longer administration of higher doses of steroids $(4 \times 30 \mathrm{mg} / \mathrm{kg}$ daily), ${ }^{3}$ not after a single $1000 \mathrm{mg}$ bolus, which is not a massive dose. Steroids are an effective measure against anaphylactic shock. ${ }^{+5}$ Are anaphylactoid reactions to steroids really common?

We tried to show the effect of steroids on vessel walls and offered angiographic evidence that occluded vessels became completely perfused 60 minutes later. A steroid bolus seems to us to be a suitable emergency treatment that does not interfere with other drugs for this condition. Any other treatment may be given simultaneously or afterwards.

Department of Ophthalmology,

Landeskrankenhaus Feldkirch,

A-6807 Austria

1 Bertram B, Wolf S, Fischer H, Schulte K, Hoberg A, Reim M Thrombolysis with plasminogen activator in retinal artery occlusion. Klin Monatsbl Augenheilk 1991;198:295-300.

2 Walker G, ed. ABPI datasheet compendium 1991-92. London Datapharm, 1991:1656-8.

3 Bush CA, Renner H, Boudoulas $\mathrm{H}$. Corticosteroids in acute myocardial infarction. Angiology 1980;31:710-6.

4 Campbell JW, Frisse M. Manuel de therapeutique medicale. $3 \mathrm{rd} \mathrm{ed}$ Paris: Médecine et Sciences Internationales, 1984.

5 Madowitz JS, Schweiger MJ. Severe anaphylactoid reaction 10

radiographic contrast media. $\mathcal{F} A M A$ 1979;241:2813-9.

\section{Side of origin of epithelial ovarian cancer}

SIR,-Two studies published in the $B M \mathcal{F}$ have been designed to test Fathalla's hypothesis that repeated trauma to ovarian epithelium caused by incessant ovulation increases the risk of ovarian cancer.' As ovulation reportedly occurs more often on the right side the authors hypothesised that ovarian tumours would occur more frequently in the right ovary. In one study the results were significant, with $59 \%$ of tumours occurring on the right side. ${ }^{2}$ In the other study the results were not significant, with $53 \%$ of tumours occurring on the right side. ${ }^{3}$

The original report that ovulation occurs more commonly from the right ovary was based on a study of only 16 women. ${ }^{+}$Moreover, it conflicted with a previous report that ovulation alternated between ovaries in $80 \%$ of cycles. "Thus the premise that ovulation occurs more often on the right side may itself not always be correct, at least for those patients at risk of ovarian cancer.

Fathalla's hypothesis is based on much broader evidence, including both clinical and epidemiological studies. This work has been reviewed elsewhere. ${ }^{6}$ More recently we have provided a molecular basis to support the hypothesis. Studies in our department have detected loss of alleles on the long arm of chromosome 17 in specimens of ovarian tumour. ${ }^{8}$ This loss of genetic material is thought to represent inactivation of an important tumour suppressor gene, and extensive studies are now under way to identify its precise location.

Pathologists have long recognised that most ovarian cancers arise on the surface of the ovary, not in the ovary itself. After the epithelial surface of the ovary has ruptured to release the ovum at ovulation the traumatic tears are repaired by repeated cell division. The loss of a tumour suppressor gene in a single epithelial cell may allow mitotic division to continue uncontrolled, leading to malignant change. Incessant ovulation increases the risk of promoting such malignant transformation. None the less, the main initiating event in malignancy is a sporadic or inherited mutation, not ovulation. Mutations have an equal chance of occurring on either side. Thus laterality in ovarian cancer is unlikely to emerge as a significant factor unless very large numbers of cases are analysed.

W S LOWRY

R J ATKINSON

Department of Oncology,

Whitla Medical Building,

Belfast City Hospital,

Belfast BT9 7BL

1 Fathalla MF. Incessant ovulation-a factor in ovarian neoplasia? Lancet 1971;ii: 163

2 Cruickshank DJ. Aetiological importance of ovulation in epithelial ovarian cancer: a population based study. $B M \mathcal{Y}$ 1990;301:524-5.

3 Johannes CB, Kaufman DW, Rosenberg L, Palmer JR, Stolley $\mathrm{PD}$, Lewis JL Jr, et al. Side of origin of epithelial ovarian
J $P \mathrm{D}$, Lewis $\mathrm{JL} \mathrm{Jr}$, et al. Side of origin

cancer. $B M \mathcal{F}$ 1992;304:27-8. (4 January.)
4 Potashink G, Insler V, Meizner I. Frequency, sequence, and side Potashink G, Insler V, Meizner I. Frequency, sequence, and side
of ovulation in women menstruating normally. $B M \mathcal{J} 1987$; of ovulation 219 .

5 Marinho AO, Sallam HN, Goessens L, Collins WP, Campbell S. Ovulation side and occurrence of mittelschmerz in spontaneous and induced ovarian cycles. $B M \mathcal{F}$ 1982;284:632.

6 Beral V. The epidemiology of ovarian cancer. In: Sharp F, Soutter WP, eds. Ovarian cancer-the way ahead. Chichester: Wiley, 1987:21-8.

7 Lowry S, Russell H, Hickey I, Atkinson R. Incessant ovulation and ovarian cancer. Lancet 1991;337:1544.

8 Russell SE, Hickey G, Lowry WS, White P, Atkinson RJ. Allele loss from chromosome 17 in ovarian cancer. Oncogene 1990;5: $1581-3$.

\section{Octreotide and Graves' ophthalmopathy}

SIR, - T C Chang and colleagues claim that octreotide is effective in Graves' ophthalmopathy.' Although there are theoretical grounds why octreotide may have a place in the treatment of this disease, the question whether it is effective remains unanswered as spontaneous improvement of Graves' ophthalmopathy is common and can occur rapidly. ${ }^{2}$ The authors might have been more convincing in their claim had they at least shown a reduction in circulating insulin-like growth factor1 concentrations as a result of treatment.

The idea is interesting, and octreotide may indeed be useful. But only a properly controlled trial is sufficient to assess the usefulness of such an expensive drug in treating Graves' ophthalmopathy.

P PERROS

Newcastle General Hospital,

Newcastle upon Tyne NE4 6BE

R A JAMES

P KENDALL-TAYLOR

Department of Medicine,

University of Newcastle upon Tyne,

Newcastle upon Tyne

1 Chang TC, Kao SCS, Huang KM. Octreotide and Graves' ophthalmopathy and pretibial myxoedema. BMf 1992;304 158. (18 January.)

2 Perros P, Weightman DR, Crombie AL, Kendall-Taylor P. Azathioprine in the treatment of thyroid associated ophthalmopathy. Acta Endocrinol 1990;122:8-12.

\section{Genitourinary tract infections in pregnancy and low birth weight}

SIR, - We thank Fiona Smaill' for referring to additional reports that support the findings of our case-control study of genitourinary infections in pregnancy and low birth weight in Australian Aboriginal women. ${ }^{2}$ We agree that a randomised controlled trial is not required. Although there have been no randomised controlled trials in our population of Australian Aboriginal women, such a trial would not be appropriate because of difficulties with follow up and compliance and for ethical reasons.

The programme we are planning is a pragmatic attempt to instigate screening and treatment of genitourinary tract infections during pregnancy in this population. The effectiveness of such a programme in reducing the incidence of preterm birth and low birth weight will be evaluated. This should indicate whether there is a preventable relation between infection and preterm birth and low birth weight in this population of disadvantaged women, many of whom experience living conditions akin to those of less developed countries.

The results of the randomised trials conducted in other populations that Smaill cites add urgency to our proposed programme.

\section{ROSALIE SCHULTZ FIONA J STANLEY} ANNE W READ PATRICIA MORICH JUDITH A Y STRATON

\section{Department of Public Health,}

Queen Elizabeth II Medical Centre,

University of Western Australia,

Perth,

Western Australia 6009

1 Smaill $\mathrm{F}$. Genitourinary tract infections in pregnancy and low birth weight. BMF 1992;304:54-5. (4 January.)

2 Schultz R, Read AW, Straton JAY, Stanley FJ, Morich P. Genitourinary tract infections in pregnancy and low birth weight: case-control study in Australian Aboriginal women. BMJ 1991;303:1369-73. (30 November.)

\section{Parent support groups}

SIR, - P Morris Jones raises anxieties that "bitter and angry" parents may dominate parent support groups and so undermine their value unless a professional keeps an eye on them.

From time to time Action for Sick Children receives telephone calls and letters from such parents; in most cases these parents believe that no one is listening to them and they are being labelled as difficult or hysterical. Sometimes the reality is that no one can help, but in our experience the tolerance and emotional reinforcement provided by other parents can be an important factor in coming to terms with the unacceptable-namely, having a child with severe or life threatening illness. However sensitive professionals are to the intense distress that often underlines aggression, shared experience, parent to parent, is without parallel.

For this reason we are seeking to expand our advice and support to parents. This will often be in partnership with professionals, complementing and supporting their role by providing non-clinical information and an ear to listen, but above all by providing a point of contact with our local branches and specialist groups, such as those covered in the valuable directory compiled by Contact a Family. ${ }^{2}$

Action for Sick Children

London NW1 2SD

1 Jones PM. Parent support groups. BMJ 1992;304:55. (4 January.) 2 Annis J. Finding support for children with rare diseases. $B M \mathcal{J}$ 1991;303:1154. (9 November.)

\section{Bone banks}

SIR, - I agree with H I Atrah that bone banking should be organised on a professional basis to the highest standards and that some blood transfusion laboratories would be well placed to provide this service and should be encouraged.' It is essential, however, that agreed minimum quality standards are adopted, and to this end the British Orthopaedic Association has, at the request of the Department of Health, formed an allograft bone working party to establish guidelines. The current advice from the Department of Health, in contrast to that given by Atrah, is that serum from all donors (living and cadaver) must be tested for HIV antibody at donation. Subsequent testing is required for living donors except women aged over 70 . For fresh stored $\left(4^{\circ} \mathrm{C}\right)$ or frozen bone bacteriological analysis of the bone surface or bone tissue is also considered to be essential. 